\title{
SISTEMA DE AUTOMAÇÃO RESIDENCIAL ESCALÁVEL E SEM FIO UTILIZANDO TECNOLOGIAS DE BAIXO CUSTO
}

\author{
Douglas de Menezes Silva dos Santos \\ Universidade do Vale do Itajaí - UNIVALI \\ contatoddouglasdemenezes.com.br
}

\begin{abstract}
Resumo
Sistemas de automação residencial tem cada vez atraído os usuários na busca por conforto e tecnologia. No entanto, soluções disponíveis comercialmente possuem um custo elevado e um processo de instalação complexo. A solução proposta tem como objetivo reduzir o custo para soluções de automação residencial e facilitar o uso do sistema, tanto no processo de instalação, quanto na forma de interagir com o sistema, permitindo ao usuário utilizar o sistema em qualquer dispositivo que possua um navegador web e conexão com a internet.
\end{abstract}

Palavras-chave: Automação residencial. Sem fio. Baixo custo.

\section{WIRELESS AND SCALABLE HOME AUTOMATION SYSTEM USING LOW COST TECHNOLOGIES}

\begin{abstract}
Home automation systems have increasingly attracted users in search of comfort and technology. However, commercially available solutions have a high cost and a complex installation process. The proposed solution aims to reduce the cost of home automation solutions and to facilitate the use of the system, both in the installation process and on the way to interact with the system, allowing the user to use the system on any device with web browser and internet connection.
\end{abstract}

Keywords: Home Automation. Wireless. Low Cost.

\section{Introdução}

Sistemas de automação residencial têm cada vez mais atraído os usuários, gerando uma grande demanda dos usuários por tecnologias inovadoras e de baixo custo. Há uma variedade de sistemas disponíveis no mercado, visando projetos de alto padrão que, consequentemente, tem um custo elevado. A domótica é uma palavra que deriva do francês "Domotique" que pode ser identificada como uma junção das palavras "casa" ("Domus") com "automática" ("Imotique") [Roque 2012]. O objetivo da automação residencial ou domótica, é fornecer aos usuários meios mais elaborados para controlar a sua residência, como por exemplo, desligar uma lâmpada via internet ou configurar a persiana de um quarto para abrir às $07 \mathrm{~h} 00 \mathrm{~min}$.

As soluções comerciais disponíveis no mercado tem um custo relativamente alto, visto que, ao fazer a transição para um sistema de automação residencial, tende-se a automatizar a residência inteira, chegando a valores que podem facilmente ultrapassar $\mathrm{R} \$ 10.000,00$ para uma residência simples. Uma breve busca de preços na internet mostra custos para instalação e compra de equipamentos para automação residencial na faixa de $\mathrm{R} \$ 2.000,00$ a $\mathrm{R} \$ 4.000,00$ (cotados em 09/10/2012), incluindo apenas o controle básico de iluminação (liga/desliga, 
aumenta/diminui brilho) e som (liga/desliga, aumenta/diminui volume). Observa-se que as soluções comerciais que apresentam o menor custo, são as que utilizam-se de comunicação cabeada, o que pode agregar custos adicionais caso o projeto da casa não tenha previsto um canal para cabos adicionais.

\section{Sistema Proposto}

Observando as limitações e problemas encontrados nas soluções de automação residencial nacionais, foi criado um sistema de automação sem fio de baixo custo disposto na Figura 1.

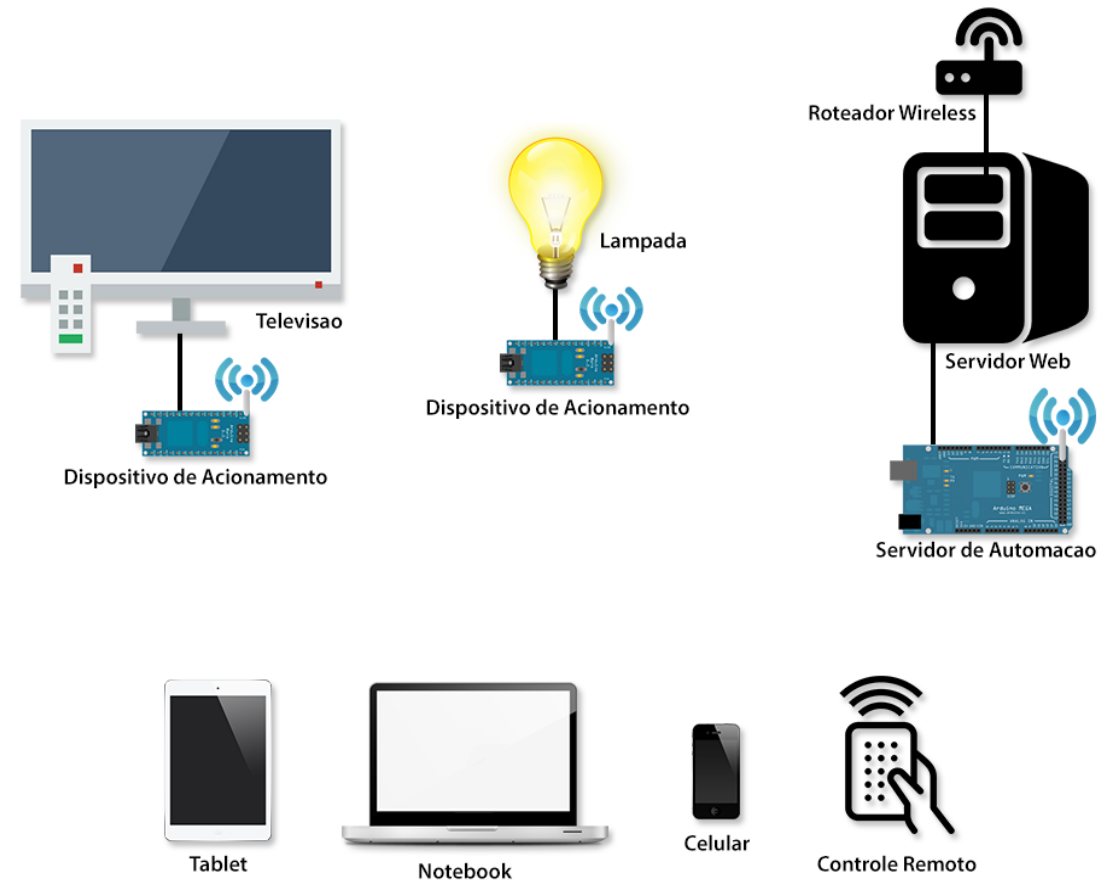

Figura 1. Estrutura do sistema de automação residencial proposto

O sistema é dividido em quatro partes:

- Dispositivo de acionamento: Este dispositivo está conectado ao equipamento o qual se deseja controlar, (ex. uma tomada).

- Servidor de automação: Este dispositivo controla todos os dispositivos de acionamento, sendo que todos os comandos são processados por ele.

- Servidor web: Através deste servidor o usuário pode configurar os ambientes da automação, quais dispositivos fazem parte de um determinado ambiente e efetuar os acionamentos. Também é nele onde toda a interface web está configurada.

- Controle remoto: Um controle remoto para controlar os dispositivos de acionamento sem a necessidade de um celular/tablet/computador.

Com este sistema, o usuário tem acesso a uma interface que permite a personalização da automação para a sua residência, podendo definir regras de acionamento, efetuar acionamentos, adicionar ou remover dispositivos, entre outros. Além da possibilidade de controle pela rede, foi testada a possibilidade de controle dos dispositivos de acionamento utilizando um controle remoto. Desta forma, caso o usuário necessite apagar uma luz, ele não precisa utilizar um dispositivo conectado à rede, acessar o servidor e enviar o comando de desligamento. Neste caso, basta apertar o botão desligar no controle remoto. 
O controle remoto, além de prover um método alternativo de controle para o sistema na ausência de computador ou celular, serve também para auxiliar o usuário no processo na transição de uma residência sem automação para uma completamente automatizada.

Grande parte das soluções comerciais necessita de um técnico ou especialista para efetuar a instalação e configuração do sistema, visto que possuem uma configuração complexa. Mudanças efetuadas na residência após o sistema estar configurado requerem um novo projeto e novamente, a necessidade de um especialista para efetuar as alterações. Visto que os usuários buscam agilidade e facilidade na instalação e utilização de sistemas que venham adquirir, o sistema foi projetado de forma que um usuário leigo possa automatizar sua casa tendo apenas um conhecimento básico em informática, eliminando a necessidade do integrador e tornando as modificações necessárias mais ágeis e baratas.

O sistema proposto consiste em uma junção de tecnologias de baixo custo, combinadas para criar um sistema de automação residencial de baixo custo sem déficit de funcionalidades. Além do baixo custo do sistema, pode-se dizer que, caso utilizado corretamente, o sistema pode também reduzir o consumo de energia elétrica em uma residência, uma vez que o sistema possui controle via internet, caso o usuário tenha esquecido algum dispositivo ligado ao sair de casa, poderá desativá-lo remotamente. É possível também criar regras de acionamentos em horários determinados pelo usuário.

No Quadro 1, exibido a seguir, é possível avaliar esta proposta frente alguns trabalhos que apresentaram maior aderência com este sistema de automação residencial.

\begin{tabular}{|c|c|c|c|c|}
\hline Característica & Trabalho 1 & Trabalho 2 & Trabalho 3 & Este trabalho \\
\hline Comunicação & Serial / TCP IP & Serial / RF & TCP IP & $\begin{array}{l}\text { Serial / TCP IP / RF / } \\
\text { IR }\end{array}$ \\
\hline Hardware & $\mathrm{PIC}$ & $\mathrm{PIC}$ & Arduino & Arduino \\
\hline Software & C\# .NET & Visual Basic & HTML / Java & PHP / JavaScript \\
\hline $\begin{array}{l}\text { Custo } \\
\text { aproximado }\end{array}$ & $\mathrm{R} \$ 600,00$ & Não informado & $\mathrm{R} \$ 200,00$ & $\mathrm{R} \$ 300,00$ \\
\hline Vantagens & $\begin{array}{l}\text { Permite o controle } \\
\text { de dispositivos via } \\
\text { Internet; é de fácil } \\
\text { instalação. }\end{array}$ & $\begin{array}{l}\text { A comunicação } \\
\text { entre os } \\
\text { dispositivos é feita } \\
\text { de forma não } \\
\text { cabeada. }\end{array}$ & $\begin{array}{l}\text { Permite o controle } \\
\text { de dispositivos via } \\
\text { Internet; o servidor } \\
\text { web é embarcado } \\
\text { no próprio } \\
\text { dispositivo; é de } \\
\text { fácil instalação; } \\
\text { possui um baixo } \\
\text { custo. }\end{array}$ & $\begin{array}{l}\text { Permite o controle de } \\
\text { dispositivos via } \\
\text { Internet; possui um } \\
\text { baixo custo; } \\
\text { comunicação entre os } \\
\text { dispositivos é feita de } \\
\text { forma não cabeada; } \\
\text { permite o controle } \\
\text { local via controle } \\
\text { remoto infravermelho; } \\
\text { é de fácil instalação. }\end{array}$ \\
\hline Desvantagens & 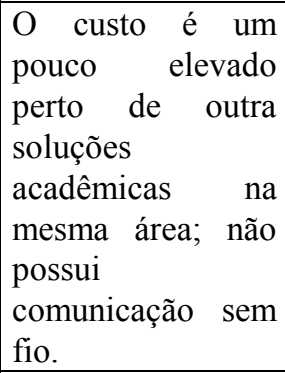 & $\begin{array}{lr}\text { Não permite } & \text { o } \\
\text { controle } & \text { de } \\
\text { dispositivos via } \\
\text { internet, o que } \\
\text { limita o escopo de } \\
\text { utilização. }\end{array}$ & 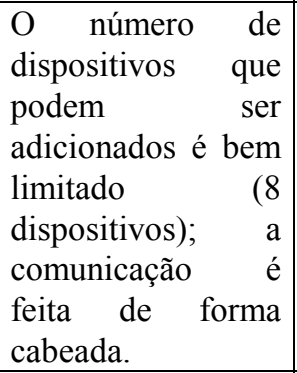 & $\begin{array}{l}\text { Necessita de um } \\
\text { servidor separado para } \\
\text { armazenar o banco de } \\
\text { dados e as páginas } \\
\text { web. }\end{array}$ \\
\hline Referência & [Quinderé 2009] & [De Almeida 2009] & [Zandoná 2012] & \\
\hline
\end{tabular}

Quadro 1. Análise comparativa do estado da arte 


\section{Desenvolvimento}

Dado que o projeto deverá rodar em pelo menos três dispositivos diferentes (computador, tablet e celular) é necessária a criação de um design diferente para cada um dos dispositivos, bem como um código que não demande muitos recursos do processador ou muita banda de rede, visto que o usuário pode estar em uma rede de acesso móvel de baixa velocidade. A criação de designs adaptativos é considerada complexa, visto que a mesma página deve ser apresentada de formas diferentes em dispositivos distintos, porém, criar uma página para cada dispositivo acarretaria em código desnecessário, limitação na escalabilidade, bem como, quanto mais dispositivos forem ser utilizados, mais código será necessário.

As telas do sistema foram projetadas visando a facilidade no uso e a adaptabilidade da interface para diversos cenários de utilização.

Com isso em vista, foi utilizado o Twitter Bootstrap, que até um certo nível, pode-se definir como um framework. O Twitter Bootstrap é um conjunto de estilos CSS e funções em JavaScript que podem facilmente serem utilizados para reaproveitar o mesmo design em diferentes dispositivos. Ele lida com questões do design adaptativos como por exemplo: um Apple iPad 4, possui uma resolução maior que 1366×768, a mais comum em notebooks, porém, mesmo tendo uma resolução maior, deve-se apresentar um conteúdo destinado a tablets e não para computadores. O Twitter Bootstrap surgiu teve sua primeira versão lançada em Agosto de 2011, desde então, vem cada vez mais sendo utilizado no desenvolvimento de websites, facilitando a criação das telas do sistema, permitindo ao desenvolvedor dedicar mais tempo nas funcionalidades do sistema. Em conjunto com o Twitter Bootstrap, foi utilizado o framework jQuery, buscando agilizar o carregamento de páginas, e fazê-lo de forma dinâmica, visando economizar recursos.

Os componentes do sistema foram escolhidos visando o baixo custo e facilidade de acesso. Para a parte de hardware, é utilizada a plataforma Arduino (2013), onde para o servidor de automação será utilizado um Arduino Mega 2560, dado que o mesmo possui uma quantidade maior de portas de entrada e saída, bem como uma memória RAM e memória Flash maior, quando comparado ao Arduino UNO. O Arduino UNO será utilizado para as interfaces de acionamento, tanto para acionamentos simples, quanto para o controle do televisor.

A tecnologia utilizada para a comunicação sem fio entre os Arduinos é a radiofrequência (RF), onde é utilizado o transceiver de radiofrequência NRF24L01+. Para tratar da comunicação entre os diferentes Arduinos, foi utilizada a biblioteca NRF24L01, projetada especificamente para o transceiver anteriormente citado, a qual faz todo o tratamento do protocolo de RF e endereçamento, permitindo ao usuário enviar e receber dados via RF com poucas linhas de código.

A comunicação com o televisor foi realizada via infravermelho, sendo utilizado um LED IR para emitir os comandos IR para o televisor, e um receptor de infravermelho VS1838B, para receber os comandos de um controle remoto. Para tratar do protocolo infravermelho foi utilizada a biblioteca IRremote, projetada para codificação e decodificação de comandos IR. Dado que em geral cada empresa possui um protocolo de IR diferente, a biblioteca IRremote possui suporte a uma grande parte delas.

Para o servidor web, o qual deverá ser instalado em um computador, foi utilizado o software VertrigoServ, que nada mais é do que um pacote de softwares que inclui o Apache, MySQL, interpretador PHP entre outros, necessários para o funcionamento correto da solução. O mesmo foi escolhido pela facilidade de instalação, sendo que em poucos passos já é possível ter o servidor rodando na máquina sem conhecimentos avançados de informática. 
Por fim, para a implementação dos códigos, tratando-se da parte de hardware que envolve o Arduino, foi utilizada a IDE fornecida pela própria empresa Arduino. Já para a implementação dos diversos códigos, não foi utilizado nenhuma IDE específica, apenas o Notepad++, uma versão melhorada do bloco de notas que possui suporte a realce de sintaxe para diversas linguagens.

\subsection{Interface Web}

Ao projetar o design do sistema, foi necessário levar em consideração que a mesma página seria apresentada em diferentes dispositivos, de diferentes tamanhos. Foi necessário também criar uma interface que visa a facilidade de uso, de forma que uma pessoa leiga possa utilizar o sistema sem dificuldades. Logo, a interface foi criada visando a adaptação para os diferentes dispositivos e a quantidade de informações a serem carregadas em cada página. A página principal do sistema sendo exibida em um iPhone 4S pode ser visualizada na Figura 2.

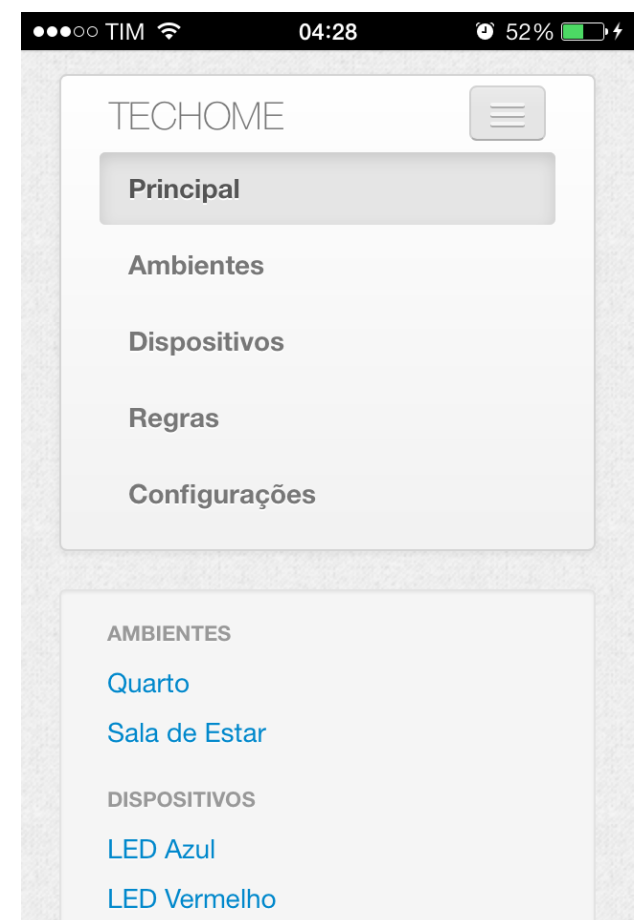

Figura 2. Página principal do sistema exibida em um iPhone 4S

As páginas de configuração de ambientes, dispositivos e regras foram projetadas seguindo a mesma base: é apresentada uma tabela com as entradas registradas no banco de dados e um botão para que seja adicionada uma nova, bem como editar ou excluir uma entrada.

É através da interface web que o usuário efetua as configurações do sistema e interage com os dispositivos cadastrados, bem como acompanhar o status de um determinado dispositivo. Todas as funções do sistema podem ser utilizadas em qualquer dispositivo dotado de conexão com a internet e um navegador web, dando liberdade ao usuário para interagir com sua residência no dispositivo com o qual esteja mais familiarizado. Na Figura 3 é exibida a tela de controle da interface de acionamento simples sendo exibida em um computador e, na Figura 4 a tela de controle para a interface de acionamento infravermelho sendo exibida em um iPad 4. 


\section{LED Azul - Sala de Estar}

\section{Ligar Desligar}

Status: Ligado - em Oct 152013 12:14 PM

Fechar

Figura 3. Tela de controle da interface de acionamento simples

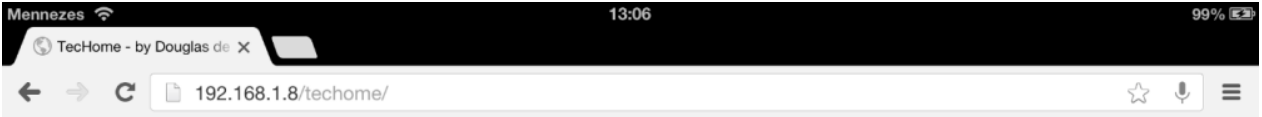

Figura 4. Tela de controle da interface de acionamento infravermelho sendo exibida em um iPad 4

\subsection{Hardware}

Para o servidor de automação foi utilizado um Arduino Mega 2560. O servidor de automação tem como função receber as requisições enviadas através do servidor web, processá-las e encaminhar para o dispositivo de destino. Foram acoplados ao Arduino: um shield Ethernet e um transceiver de radiofrequência NRF24L01+. Uma foto do servidor montado pode ser visualizada na Figura 5. 


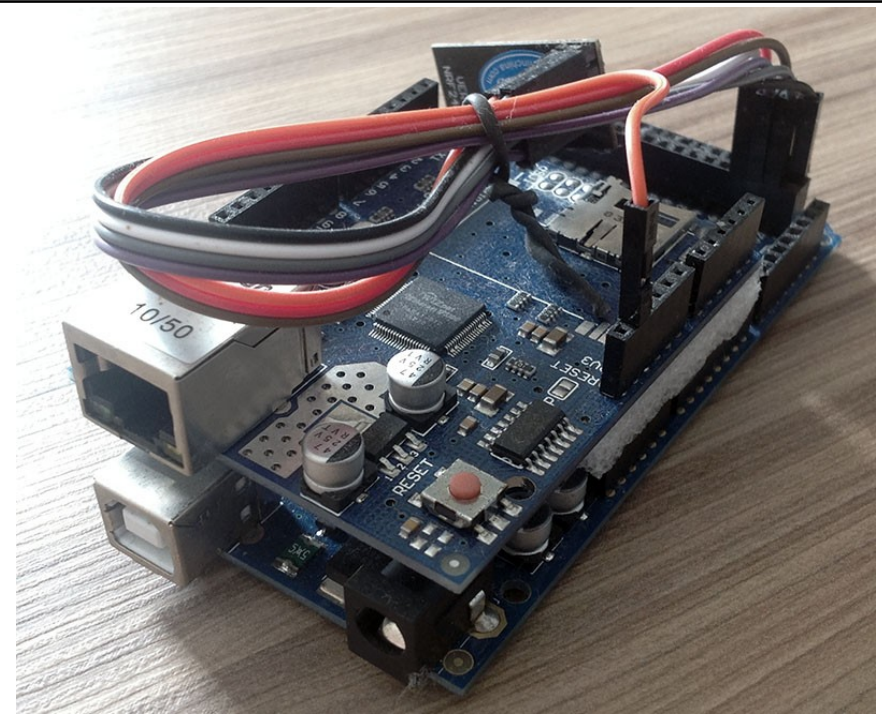

Figura 5. Servidor de Automação

$\mathrm{Na}$ interface de acionamento simples, para efetuar os testes e a validação do sistema, o relê foi substituído por um LED. Foi acoplada a interface de acionamento simples um receptor de infravermelho, responsável por receber comandos do controle remoto do sistema. A interface de acionamento simples pode ser visualizada na Figura 6.

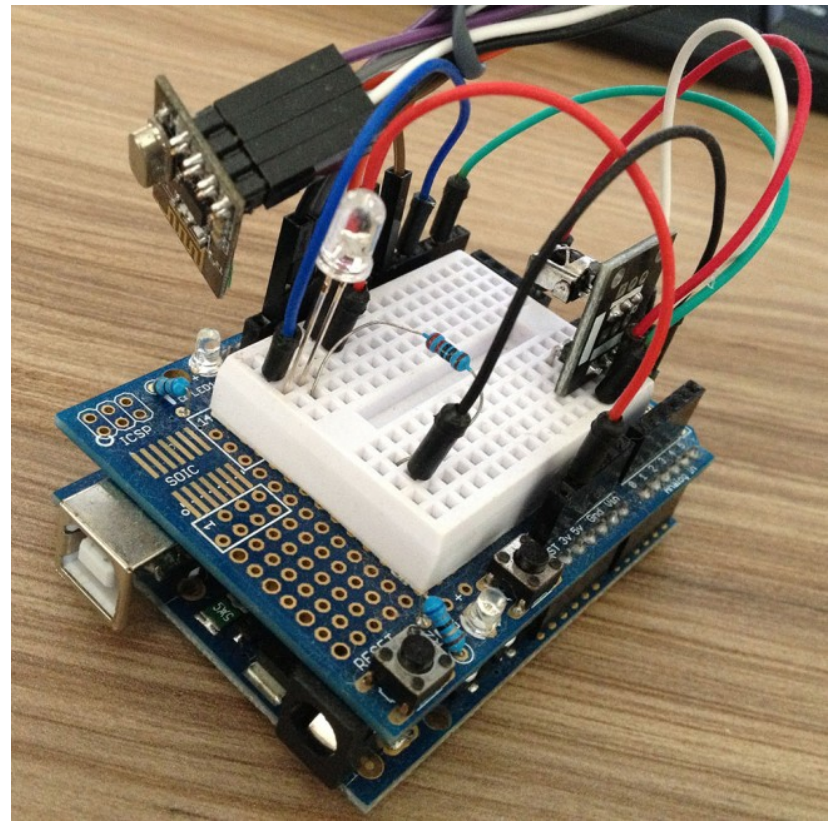

Figura 6. Interface de acionamento simples

A interface de acionamento infravermelho possui apenas um LED emissor de IR, responsável por enviar os comandos para o televisor. A única forma de controle com a interface de acionamento infravermelho é pela interface web.

\section{Design do experimento}

Para este experimento, o servidor web utilizado para armazenar o banco de dados, sendo responsável por apresentar e manipular as páginas web é executado em um notebook da marca Samsung, modelo NP55P5C-AD1BR. Lembrando que este servidor é utilizado também para efetuar os testes de acionamento dos dispositivos. Para os testes de compatibilidade da 
apresentação das páginas web em outros dispositivos, os testes foram feitos em um Apple iPad 4 de 32Gb, um Samsung Galaxy S3 Mini e um Apple iPhone 4S de 16Gb. É importante ressaltar que o servidor web pode também ser utilizado para controlar o sistema.

$O$ testes de navegação foram feitos em todos os dispositivos através do navegador de internet Google Chrome, o qual está disponível para as três plataformas (Windows, Android e iOS).

Para os testes e validação dos dispositivos, foi configurada uma amostra de 2 dispositivos de acionamento simples e 1 dispositivo infravermelho. No caso dos dispositivos de acionamento simples, foram acionados 2 relés, os quais poderão estar conectados à cargas

Para o dispositivo de infravermelho, foi utilizada uma televisão da marca Samsung, modelo UE40EH6030, a qual possui comunicação infravermelho. Lembrando que os comandos infravermelho variam para cada modelo de televisor, este experimento contemplou apenas este modelo de televisor. Na Figura 7 são exibidos todos os dispositivos utilizados na fase de testes.

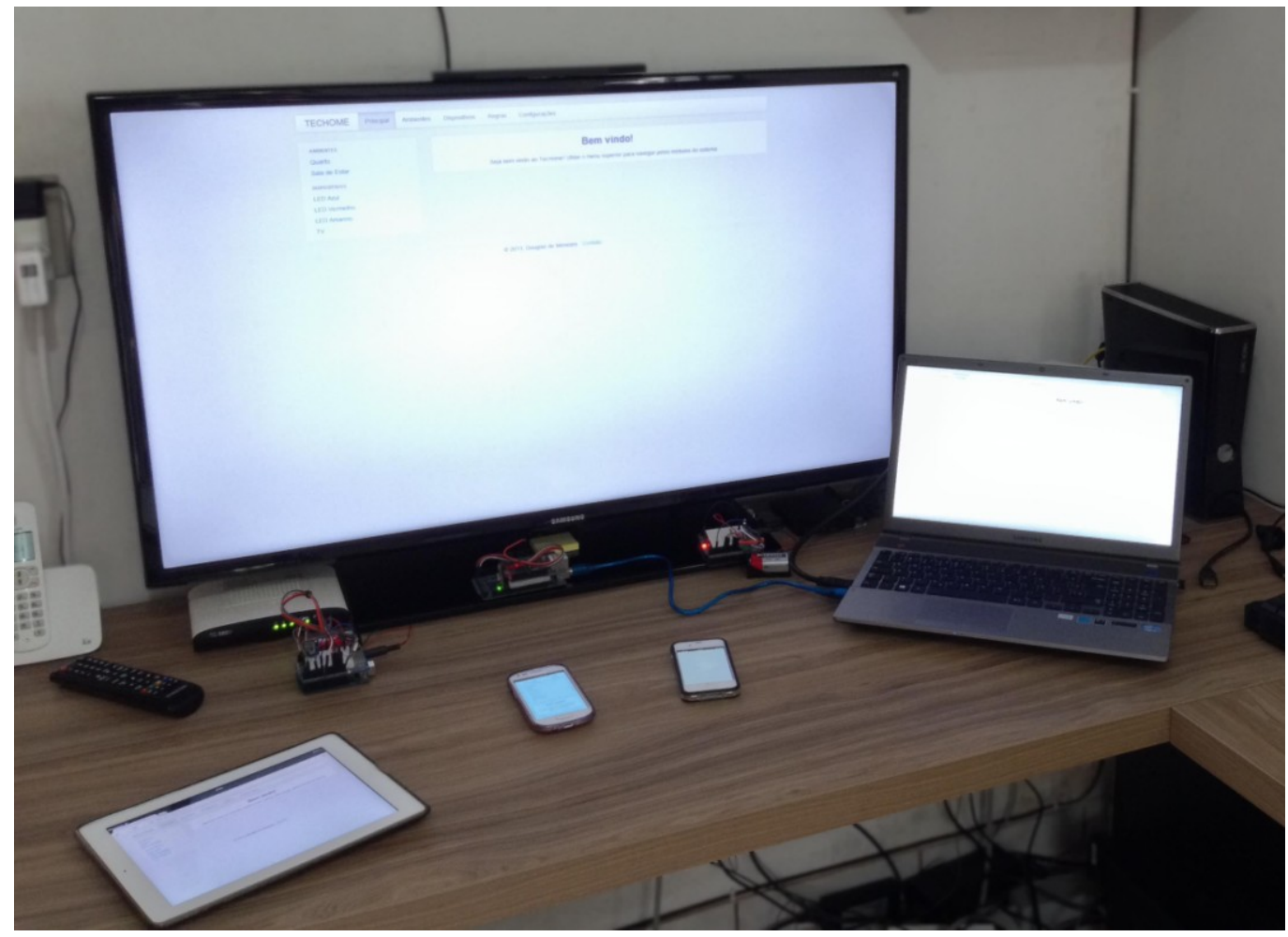

Figura 7. Dispositivos utilizados nos testes do sistema

\section{Resultados}

Simulando um ambiente de uso real, o sistema se comportou de forma satisfatória, permitindo ao usuário controlar os dispositivos do sistema da forma projetada. Foi verificado também, que além dos dispositivos de teste especificados (Notebook, Apple iPad 4, Apple iPhone 4S e Samsung Galaxy S3 Mini), foi possível interagir com o sistema em outros dispositivos através do navegador web, embora nestes casos tenham apresentado alguns problemas de exibição em função dos navegadores. Alguns dos dispositivos testados foram o Nintendo Wii e o Microsoft XBOX360. Na Figura 8, disposta a seguir, é possível visualizar como o sistema é exibido no navegador do Nintendo Wii. Embora a experiência visual seja reduzida, o usuário consegue ter acesso à todas as funcionalidades do sistema sem nenhuma restrição. 


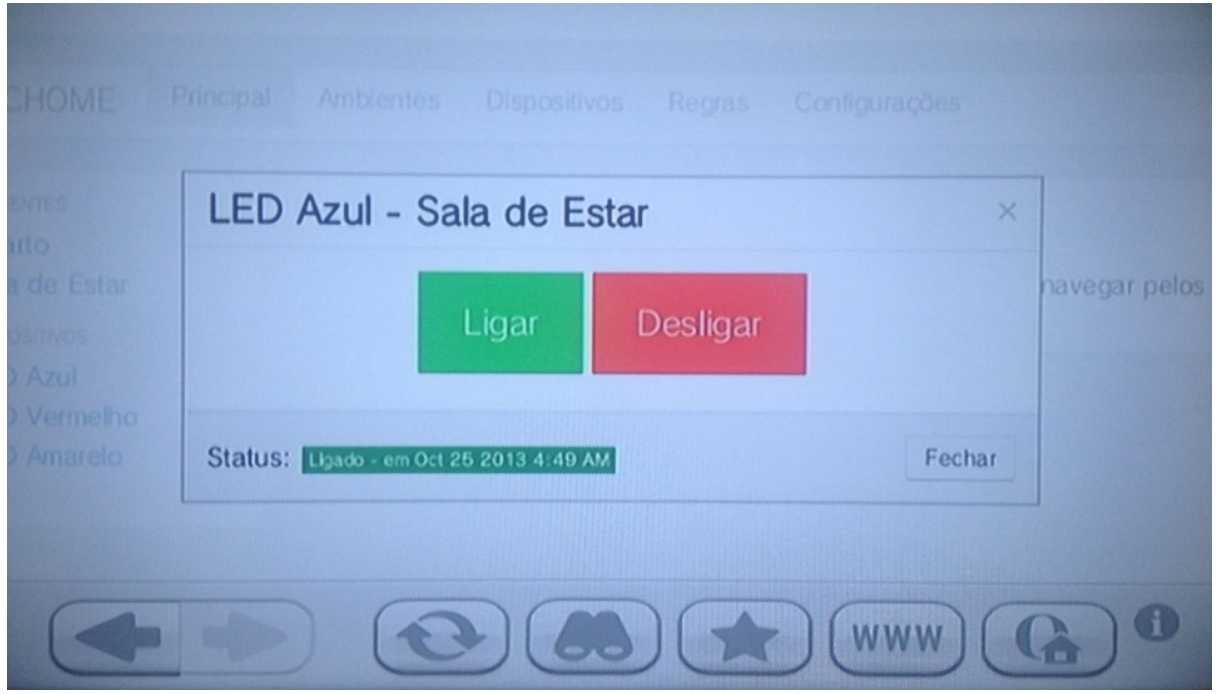

Figura 8. Sistema sendo exibido no navegador do Nintendo Wii

As interfaces de acionamento simples e infravermelho, ao serem alimentadas por uma bateria de $9 \mathrm{~V}$, permaneceram ligadas por 2 e 4 dias, respectivamente (. Dentre os testes efetuados, alguns deles foram:

- Teste da interface web

Descrição: Testar todas as páginas da interface web em cada uma das plataformas do sistema (computador/tablet/celular).

Resultados: Em cada um dos dispositivos testados (Computador, Apple iPad 4, Apple iPhone 4S e Samsung Galaxy S3 Mini) o sistema foi exibido de forma correta. Alguns testes foram feitos também em outras plataformas, sendo elas o Nintendo Wii e Microsoft XBOX 360, onde em ambos foi possível interagir com o sistema.

Problemas observados: As animações no Apple iPhone 4S e Samsung Galaxy S3 Mini são executadas um pouco mais lentamente do que no computador e no Apple iPad 4, o que pode ocorrer devido a uma menor capacidade gráfica desses dispositivos.

- Teste da interface de acionamento infravermelho via web

Descrição: Enviar comandos para a IAI através da interface web, como desligar/ligar o televisor, aumentar e diminuir o volume, entre outros em cada uma das plataformas (computador/tablet/celular).

Resultados: A IAI funcionou como o esperado, podendo ser controlada através da interface web. Com os comandos disponíveis no sistema, foi possível controlar as principais funções do televisor e navegar através dos menus sem dificuldade.

- Teste da interface de acionamento simples via controle remoto

Descrição: Ligar/Desligar a IAS utilizando o controle remoto do sistema.

Resultados: A IAS funcionou como o esperado, interpretando e executando corretamente todos os comandos enviados pelo controle.

Problemas observados: Em distâncias superiores a cinco metros ou com um objeto sólido entre o controle remoto e o dispositivo, a IAS não conseguiu captar e executar todos os comandos.

Problemas observados: As animações no Apple iPhone 4S e Samsung Galaxy S3 Mini são executadas um pouco mais lentamente do que no computador e no Apple iPad 4, o que pode ocorrer devido a uma menor capacidade gráfica desses dispositivos. 


\section{Considerações Finais}

Utilizando diversas tecnologias, foi possível desenvolver um sistema de automação residencial de baixo custo e sem déficit de funcionalidades, quando comparado a soluções comerciais. Analisando as soluções acadêmicas e comerciais, é possível dizer que o sistema implementado está alinhado às necessidades do usuário.

A interface do sistema foi projetada visando a facilidade de uso e o controle remoto, adicionado ao sistema visando facilitar a transição entre uma residência sem automação para uma com automação, além de permitir uma forma de controle alternativo na ausência de um dispositivo conectado à internet. Foi executado um teste superficial sobre a facilidade do uso do sistema, foi solicitado a usuários com conhecimento básico em informática acessar o sistema e ligar/desligar um dos dispositivos, tarefa que foi executada sem dificuldade pelos usuários. No entanto, testes mais elaborados devem ser efetuados para que seja comprovada a facilidade de uso do sistema no geral.

Foi necessário analisar o padrão de mensagens utilizado pela fabricante do televisor utilizado para os testes, tornando possível ao sistema interagir com o televisor como se fosse o controle remoto do televisor. É importante ressaltar que, as mensagens utilizadas fazem parte do conjunto de instruções do televisor Samsung UE40EH6030. Para que seja feita a comunicação com televisores de outras marcas, é necessário adaptar o sistema para o padrão de mensagens da fabricante. Foram executados testes em outros televisores da marca Samsung, onde a maioria dos comandos foram interpretados.

Além do protocolo infravermelho, foi criado um padrão de mensagens para facilitar a comunicação dos dispositivos do sistema. Este, feito utilizando radiofrequência. Para a comunicação entre os servidores foi utilizado o protocolo serial.

Além dos dispositivos testados, verificou-se também que o sistema foi apresentado de forma satisfatória em diversos outros dispositivos, o que inclui smartphones de baixo custo, como Samsung Galaxy 5, e consoles de videogame, como o Nintendo Wii, Microsoft XBOX360, Sony Playstation 3 e Sony Playstation Vita. Em testes superficiais, verificou-se que o sistema funcionou corretamente no smartphone Apple iPhone 5 e Samsung Galaxy S4. É importante ressaltar que, embora o sistema tenha funcionado nos dispositivos anteriormente citados, foram executados apenas testes superficiais, tendo em vista verificar a variedade de dispositivos suportados pelo sistema.

\section{Referências}

ARDUINO. Arduino - HomePage. Disponível em $<$ http://www.arduino.cc/ $>$. Acesso em: 07 jun. 2014.

DE ALMEIDA, Alexandre V.; 2009. Implementação de um Sistema de Automação Residencial Modular Sem Fio: Módulo Periférico. Disponível em http://www.tcc.sc.usp.br/tce/disponiveis/18/180500/tce-23042010155834/publico/Almeida_Alexandre_Vaz_de_2.pdf. Acesso em: 07 jun. 2014.

QUINDERÉ, Patrick R. F., 2009. Casa Inteligente - Um Protótipo de Sistema de Automação Residencial de Baixo Custo. Disponível em http://www.ffb.edu.br/sites/default/files/tcc-20082-patrick-romero-frota-quindere.pdf. Acesso em: 07 jun. 2014.

ROQUE, António. Introdução a domótica. Disponível em: http://www.antonioroque.com/textos.asp?idCat=11\&idArtigo=12. Acesso em: 30 out. 2012. 
Universidade do Estado de Santa Catarina

Centro de Educação Superior do Alto Vale do Itajaí

ZANDONÁ, Pablo T.; 2012. Interface Homem-Máquina para Domótica Baseada em Tecnologias Web em um Servidor Embarcado. Disponível em http://www.aedb.br/seget/artigos12/41016425.pdf>. Acesso em: 07 jun. 2014. 